\title{
Ventilated Illuminating Wall (VIW): Natural ventilation numerical analysis and comparison with experimental results
}

\author{
O. Boccia ${ }^{*}$, F. Chella, P. Zazzini \\ D.S.S.A.R.R., Faculty if Architecture University “G. D’Annunzio”, Pescara, Italy \\ * Corresponding author. Tel: +39 854537291, Fax: +39 854537268, E-mail:oreste.boccia@libero.it
}

\begin{abstract}
The authors propose a comparison among the first experimental and numerical results of an analysis carried out about the theme of the natural ventilation and the energy efficiency relatively to a device called Ventilated Illuminating Wall (VIW). The VIW is represented by a 1:1 prototype scale model, constituted by a precast removable manufactured product set to a window of the room, able both to transport the natural light, captured by the coverage, in underground area, and to introduce outside air for the required indoor ventilation. The experimental data, object of a work previously carried out, are obtained from temperature and air speed measurements in different points inside the tested room.

Based on s ome meaningful environmental parameters, internal and external temperature of the building, direction and wind speed in different times of the year, the device performances are evaluated through the software Fluent/Airpak, able to make fluid dynamics modeling and simulations, with the aim to calculate the air flow rate distributions, air speed and temperature field inside the room. The numerical analysis is carried out in steady state condition and produces results that, sometimes, are overestimated with respect to experimental ones. The results may be improved by a transient analysis.
\end{abstract}

Keywords: Ventilated illuminating wall, Natural ventilation, Energy efficiency, Thermal comfort, CFD.

\section{Introduction}

The energy consumption of buildings takes a significant role in the energy question, because buildings are responsible of about $40 \%$ of the whole world energy demand [1]. In buildings in which underground areas are present the energy consumption is increased because they need to be artificially enlighten and ventilated. Particularly mechanical ventilation is generally adopted in these cases. Moreover, when internal environments of buildings are used as museums or exhibition rooms, they need a particularly uniform luminance distribution of the walls with low illuminances all over the work plane in order to allow the correct perception of works of art on di splay, particularly in the case of paintings, with the right contrast of luminances between the visual task and the background, avoiding the risk of glare. Since this risk is often present when natural light is introduced in the room through traditional daylight sources, for the presence of intense direct solar radiations that can be reflected by shiny walls, in these cases it is better avoiding natural light entering through windows or skylights and technological daylight systems, as light pipes or double light pipes [2, 3], can be used in order to provide better conditions for visual comfort. The absence of windows makes it impossible the natural ventilation of the room. In some cases light pipes, used to introduce daylight in underground areas, are equipped with technological systems able to ensure air extraction from the room $[4,5]$. The innovative system presented in this paper, named Ventilated Illuminating Wall (VIW), has been developed by the authors in order to simultaneously allow natural lighting and ventilation for the environment. So, when underground areas are used or rooms without any direct interface to outwards the VIW allows air ventilation and natural light inlet, giving the room a high quality of light and comfortable conditions of indoor air. It is a combination of a daylight transport system and a passive solar system set up in a real scale by the authors. In this paper a numerical analysis of the device is presented and the results are compared with some experimental data of air circulation parameters. 


\section{Methodology}

Moving from the availability of some data obtained by the experimental analysis, such as internal and external temperatures, wind direction and speed in different times of the year, the authors carried out a numerical analysis with the aim to evaluate the performances obtainable by the VIW. In particular they analyzed the system in steady state conditions and compared the numerical results with experimental ones in order to test the used numerical code with the aim to be sure that it is a suitable tool of analyzing the performances of the VIW.

\subsection{Numerical analysis}

The numerical analysis was carried out by the software Fluent with the aim to calculate the air flow rate distributions, air speed and temperature field inside the room. Due to the complexity of the geometry and the 3D characteristics of the flow, only numerical methods, often referred to as CFD, can be used to solve the velocity, pressure and temperature field. The fundamental set of partial differential equations (PDEs) describing fluid flow, known as the Navier-Stokes equations [6], can be applied to the problem under consideration, assuming the hypothesis of incompressible flow.

The governing PDEs of fluid flow (conservation of mass, momentum and energy) can be written in a generic form as the following:

$$
\frac{\partial(\rho \Phi)}{\partial t}+\operatorname{div}(\rho \vec{v} \Phi)=\operatorname{div}\left(\Gamma_{\phi} \overrightarrow{\operatorname{grad}} \Phi\right)+S_{\phi}
$$

in which $\Phi$ represents the predicted variable, $\rho$ the density of the fluid, $\Gamma_{\Phi}$ the diffusion coefficient and $\mathrm{S}_{\Phi}$ the source term. If $\Phi=1$ the continuity equation is obtained. The actual form of the variables in Eq. (1) is summarized in Table1.

\begin{tabular}{ccc}
\multicolumn{3}{c}{ Table 1 - Variables in eq. 1} \\
\hline $\boldsymbol{\Phi}$ & $\boldsymbol{\Gamma}_{\boldsymbol{\Phi}}$ & $\mathbf{S}_{\Phi}$ \\
$\mathrm{v}_{\mathrm{x}}$ & $\mu_{\mathrm{eff}}$ & $-\partial P / \partial \mathrm{x}$ \\
& & $-\partial P / \partial y-g$ \\
$\mathrm{v}_{\mathrm{y}}$ & $\mu_{\mathrm{eff}}$ & $-\partial \mathrm{P} / \partial \mathrm{z}$ \\
& & $\mathrm{Q}$ \\
$\mathrm{v}_{\mathrm{z}}$ & $\mu_{\mathrm{eff}}$ & $-\partial \mathrm{C}$ \\
$\mathrm{C}_{\mathrm{p}} \mathrm{T}$ & $\mathrm{k}+\mathrm{k}_{\mathrm{t}}$ & $\mathrm{Q}$ \\
\hline
\end{tabular}

In order to simulate the turbulent behaviour of the flow, the RNG ("renormalization group") $\mathrm{k}-\varepsilon$ model was used, which requires the solution of two additional equations [6]. Details of turbulence model are referred in [7, 8, 9 and 10].

In this work, a commercial program package called Ansys/Fluent (Airpak) was used to simulate the airflow. It adopts a control-volume-based technique. The linearization of the discretized equations is accomplished using a first-order accuracy upwind scheme.

The pressure field is computed by the body-force-weighted scheme, which is good for highRayleigh-number natural convection flows. The problem domain was subdivided into 2.034.334 tetrahedral elements whit 352.215 nodes.

The linearized governing equations are written in an "implicit" form with respect to the dependent variable of interest. The calculated variables are used within the various 
postprocessing with the aim of determining the volume flow rate, which is a derived scalar quantity computed from the velocity field.

\subsection{Experimental analysis}

The experimental analysis was carried out by measuring the environmental parameters (air temperature and speed, wind direction and speed) in a test room properly built in the Laboratory of Technical Physics of the Faculty of Architecture of Pescara, between September and November in various external climatic conditions.

\subsection{Experimental apparatus}

The experimental apparatus is constituted by a $5 \times 3 \mathrm{~m}$ plant area room, 2,7 $\mathrm{m}$ high in which a 1:1 scale prototype of the Ventilated Illuminating Wall (VIW), is placed against the window in the north-west wall perimeter of the room. The VIW is a removable structure applied to the window able to introduce natural light and ventilation in the room. The daylight is captured by a horizontal glass plate cover applied on the top of the system and redirected in the room thanks to a multilayer highly reflecting film applied on the vertical internal closing panel of the device.

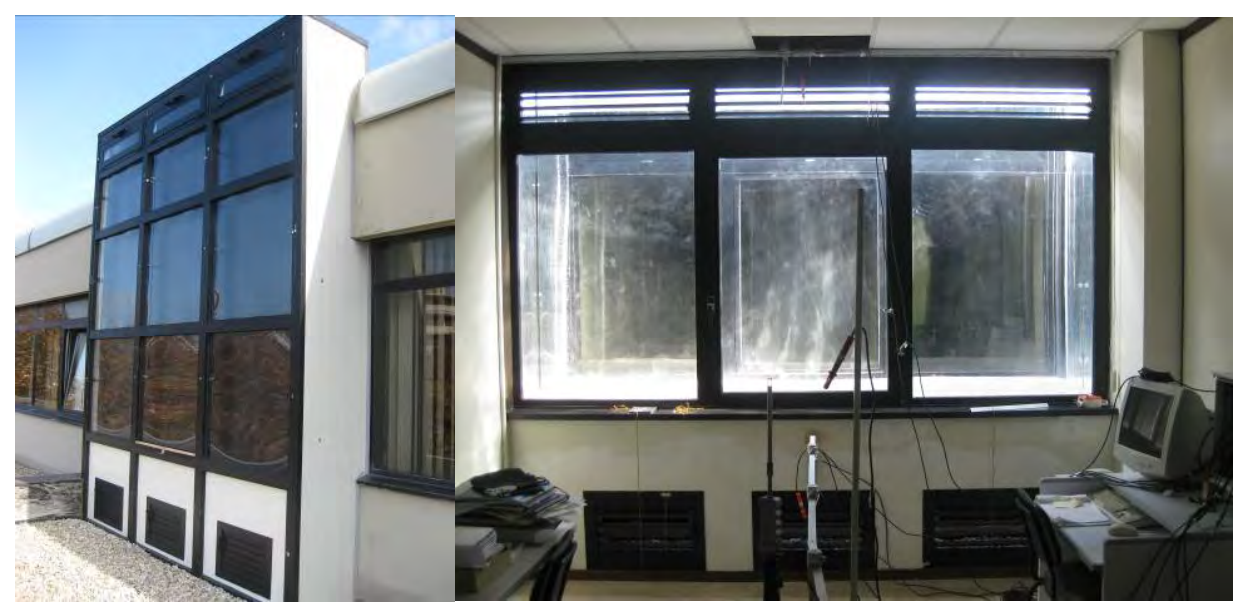

Fig. 1. External and internal views of the VIW.

(a)

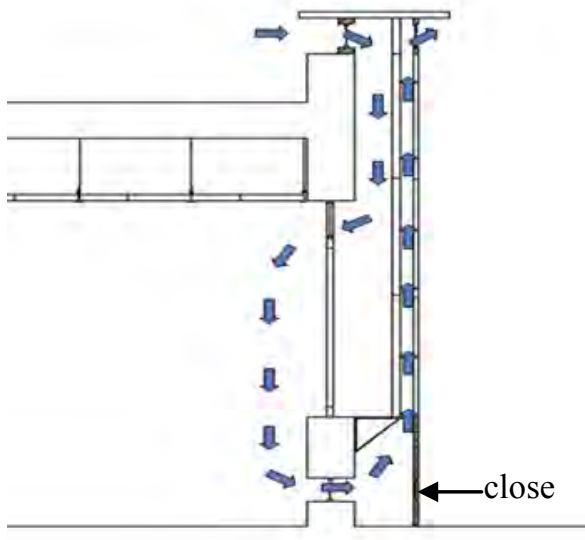

(b)

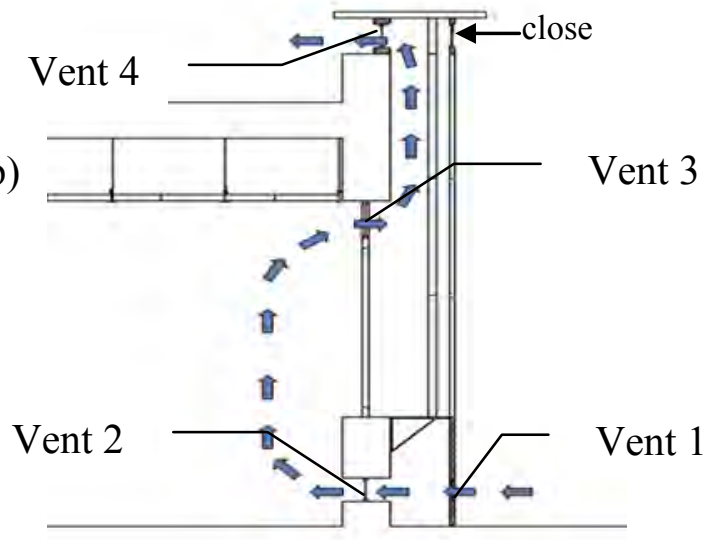

Fig. 2. Section of the VIW with qualitative air circulation and the positions of inlet and outlet vents

In Fig. 1 two external and internal views of the device are shown. The natural air circulation necessary to ensure favorable hygienic conditions in the room is guaranted by fifteen openings with wire mesh practiced on the internal and external closing panel of the system. In 
Fig. 2 a qualitative representation of the expected air circulation is shown. In particular, the Fig. 2 (a) shows the expected natural ventilation in daily summer condition and Fig. 2 (b) in night summer and in winter (night and day) conditions.

The experimental line consists of a data-logger type LSI/BABUC-ABC, characterized by 20 inputs, by which data are registered and elaborated, three internal hot wire anemometers type BSV105\#S-LSI, range $0-20 \mathrm{~m} / \mathrm{s}$, accuracy $0,01 \mathrm{~m} / \mathrm{s}$, four temperature probes PT 100 , type LSI BST101\#S - DIN IEC 751, class A; one tacho-gonioanemometer with direct output, model DNA021-LSI. The air temperature and speed are measured in three positions, in the centre of the room (1), near the opening at the bottom of the wall (2) and near the opening at the top of the wall (3), as indicated in Fig. 3.

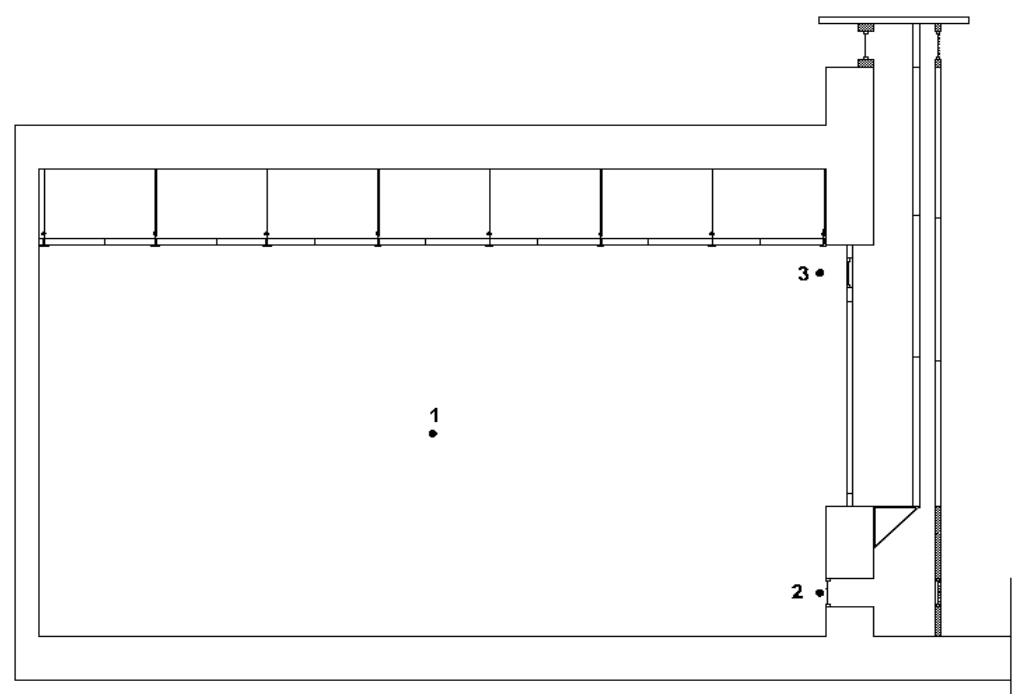

Fig 3. Air temperature and velocity sensors positions.

\section{Numerical Results}

The Figg. 4-8 show the steady numerical results by Fluent/Airpak in winter configuration, with the following boundary conditions, experimentally measured on November the $7^{\text {th }}$ at 9 a.m.:

External air temperature: $\mathrm{t}_{\mathrm{ext}}=11^{\circ} \mathrm{C}$;

Mean internal surface temperatures (floor, walls and ceiling): $\mathrm{t}_{\mathrm{s}}=22^{\circ} \mathrm{C}$;

Inlet air velocity close to the vent $1: v_{\text {in }}=0,6 \mathrm{~m} / \mathrm{s}$;

Wind direction: $210^{\circ}$ from North;

Wind velocity: $2,8 \mathrm{~m} / \mathrm{s}$.

Surface temperature on the glass plate cover: $\mathrm{t}_{\mathrm{g}}=18^{\circ} \mathrm{C}$;

Surface temperature on the external polycarbonate vertical panel: $t_{p}=15^{\circ} \mathrm{C}$.

In Fig. 4 the air speed field and the flow lines in the room are shown while in Figg. 5 and 6 the air velocity distribution on two horizontal planes, $2,4 \mathrm{~m}$ high on the floor, close to the vent 3 , and $0,3 \mathrm{~m}$ from the floor, close to the vent 2 , are illustrated. The comparison between the two images highlights the different trend of the air speed distribution in correspondence of the two inlet and outlet vents of the wall. The inlet and outlet velocities involve a mass flow rate of $=0,0854 \mathrm{~m}^{3} / \mathrm{s}$, which correspond to about 6,6 a ir changes per hour, considering that the volume of the room is equal to $46,1 \mathrm{~m}^{3}$. A second test carried with data of the same day at 2 p.m. allowed to calculate a mass flow rate of $0,058 \mathrm{~m}^{3} / \mathrm{s}$, corresponding to 4,5 air changes per hour. 

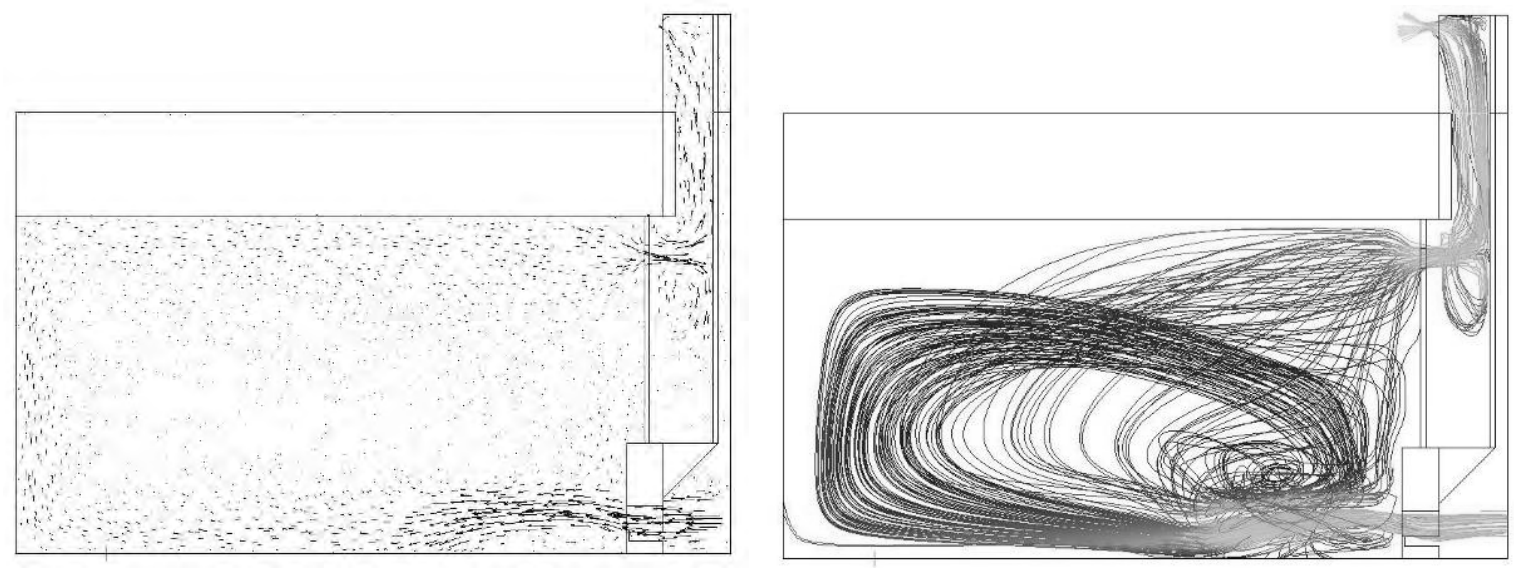

Fig 4. Air speed field and flow lines in the room.

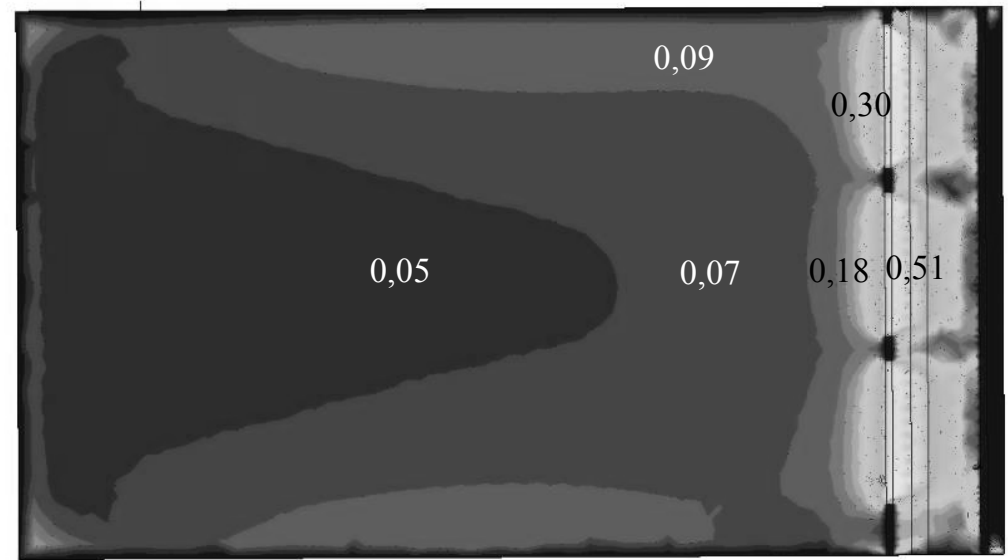

Fig 5. Air velocity $(\mathrm{m} / \mathrm{s})$ on a horizontal plane 2,4 $\mathrm{m}$ high on the floor, close to the outlet vents.

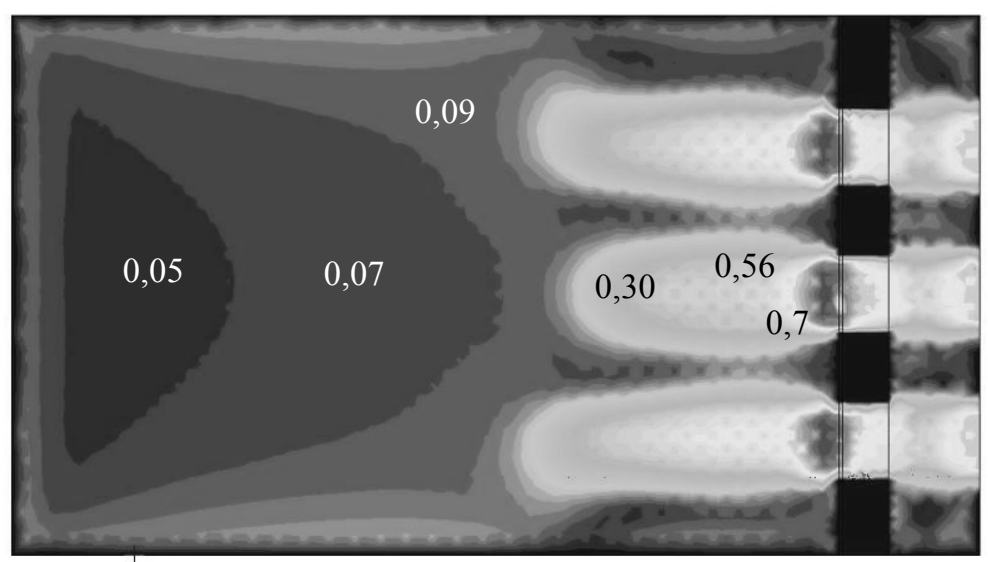

Fig 6. Air velocity $(\mathrm{m} / \mathrm{s})$ on a horizontal plane $0,3 \mathrm{~m}$ high on the floor, close to the inlet vents.

In Figg. 7 and 8 the temperature field in the room and the temperature vertical trend in the centre of the room and on a vertical plane containing the measure positions 2 and 3 close to the inlet and outlet vents are shown. It's evident how the temperature profile is influenced by the absence of any heating system and the introduction of low temperature air from the opening at the bottom of the wall, particularly close to the vents. 


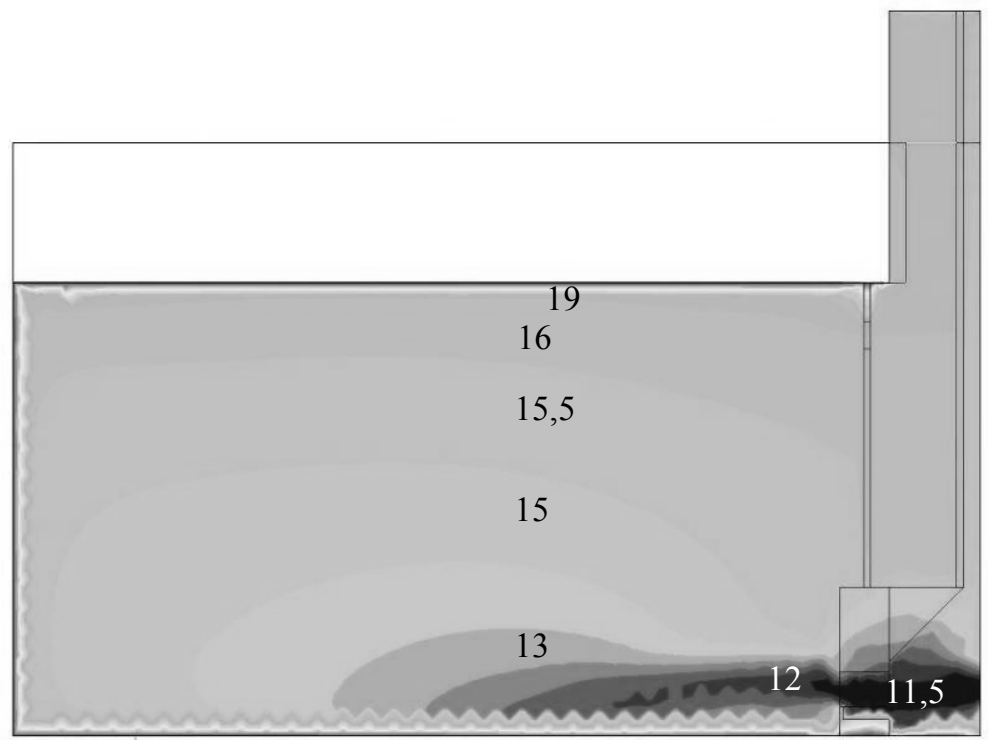

Fig 7. Air temperature field $\left({ }^{\circ} \mathrm{C}\right)$ in the room.

a

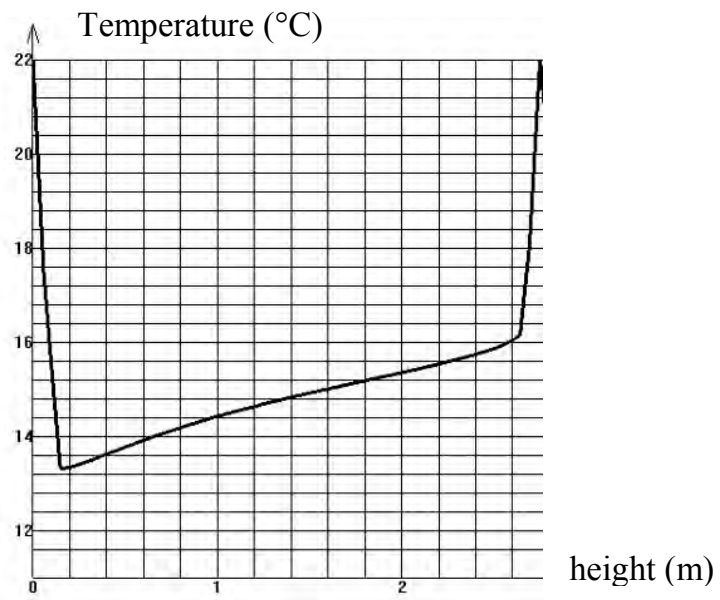

b

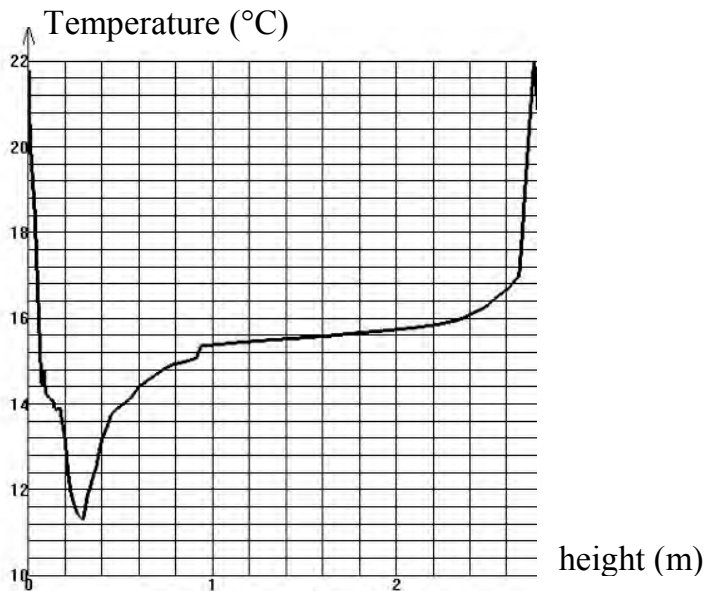

Fig 8. Air temperature vs height on the floor in the centre of the room (a) and close to the outlet and inlet vents $(b)$.

\section{Comparison between numerical and experimental results}

A comparison was carried out between the numerical results by Fluent/Airpak and the experimental data in the measure positions 1,2 and 3. The comparison was made with reference to the data of November the $7^{\text {th }}$ at two different times: 9 a.m. with a wind velocity of about $2,8 \mathrm{~m} / \mathrm{s}$ and a favourable direction $\left(210^{\circ}\right.$ from North), and 2 p.m. with a very a lower wind velocity of about $0,9 \mathrm{~m} / \mathrm{s}$ and a different wind direction $\left(45^{\circ}\right.$ from North). This last does not give any contribution to air inlet, and in this case the only stack effect allows the air circulation.

As shown in table 2, a good agreement is obtained between numerical and experimental air temperatures both at 9 a.m. and at $2 \mathrm{p} \mathrm{.m.} \mathrm{On} \mathrm{the} \mathrm{contrary,} \mathrm{the} \mathrm{comparison} \mathrm{between} \mathrm{the}$ numerical and experimental air velocities shows a good agreement in position 1, in the centre of the room, while a more significant discrepancy is verified in positions 2 and 3, close to the air inlet and outlet vents, partially due to the influence of the boundary conditions. This disagreement is verified in both the situations considered. 
As an example, in Figg. 9 and 10 the air velocities comparison is shown between data at 9 a.m.

Table 2 - Comparison between numerical and experimental air temperature $T_{a}$

Position $1 \quad$ Position $2 \quad$ Position 3

Exp. Num. Exp. Num. Exp. Num.

\begin{tabular}{lllllll}
$\mathrm{T}_{\mathrm{a}}\left({ }^{\circ} \mathrm{C}\right)$ at $9 \mathrm{am}$ & 14,75 & 14.74 & 11,77 & 11.37 & 17,74 & 16.1 \\
$\mathrm{~T}_{\mathrm{a}}\left({ }^{\circ} \mathrm{C}\right)$ at $2 \mathrm{pm}$ & 17,4 & 18,7 & 16,8 & 16,8 & 18,2 & 19,3 \\
\hline
\end{tabular}

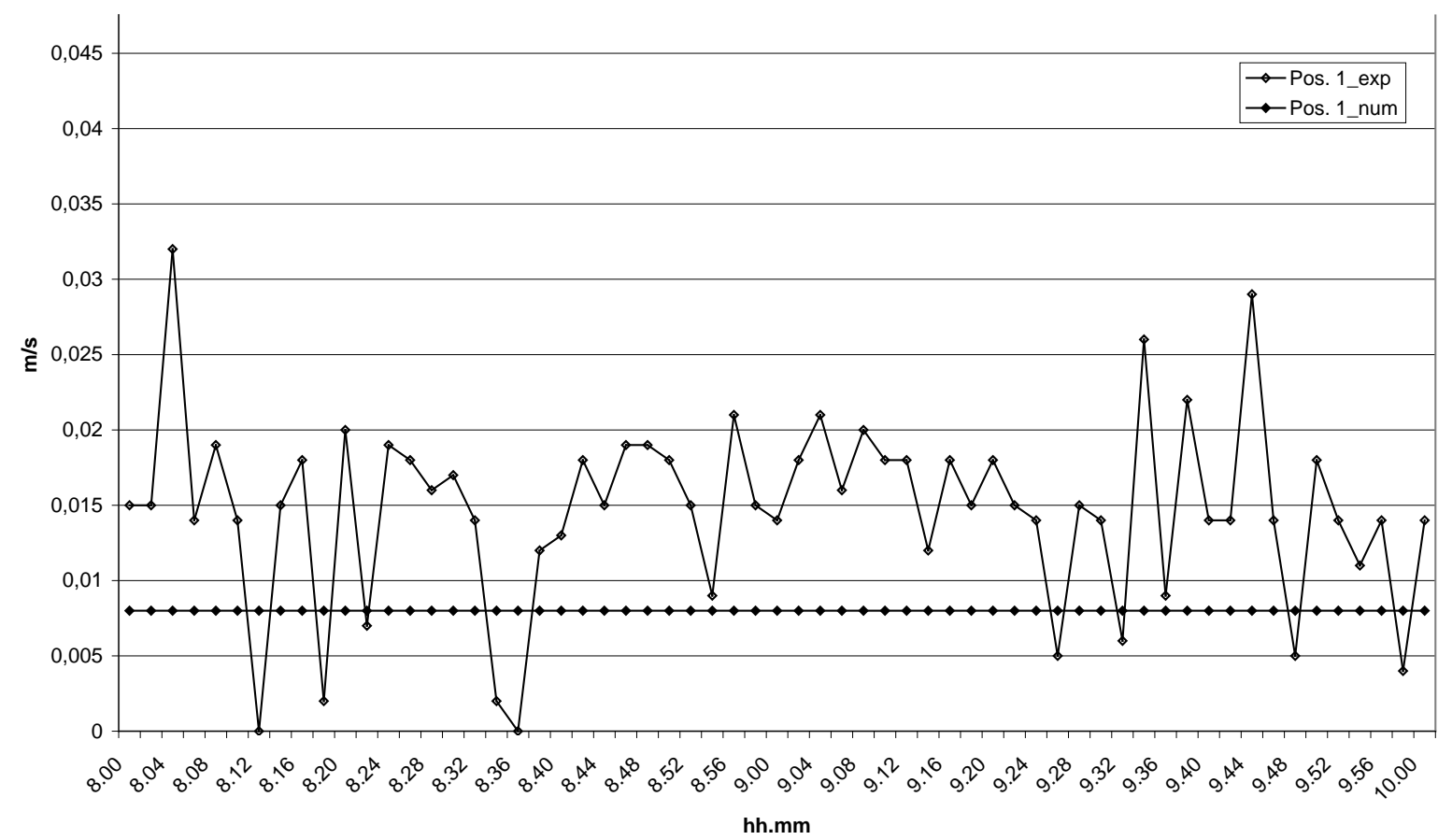

Fig 9. Experimental and numerical air velocity in position 1 in the centre of the room

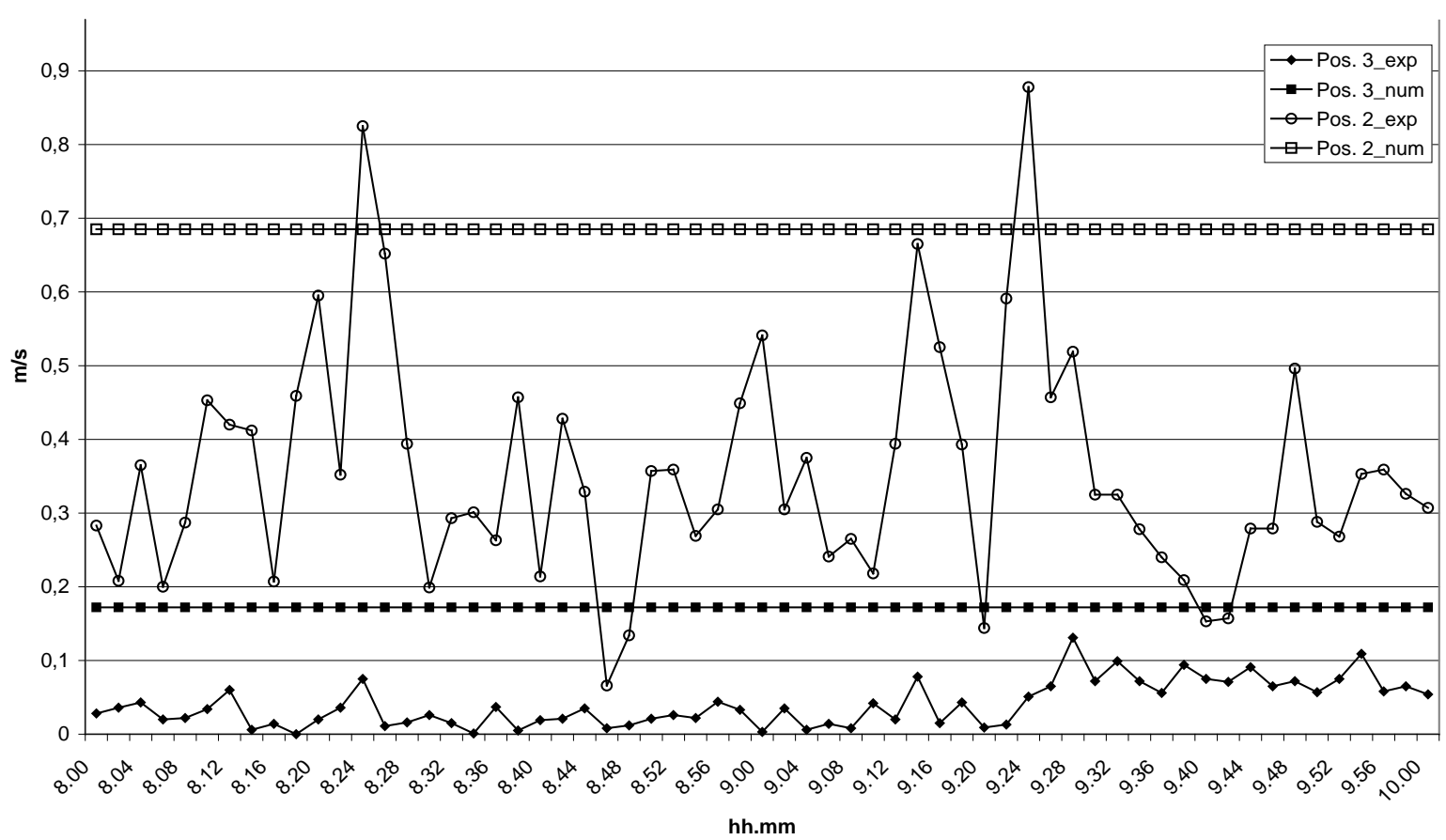

Fig 10. Experimental and numerical air velocity in positions 2 and 3, close to the inlet and outlet vents 


\section{Conclusions}

The numerical analysis carried out by the sw Fluent/Airpak allows to determine the main features of the VIW in terms of its capacity of making an efficacy natural ventilation in rooms without direct interface to outwards. Data about the temperature field are satisfactory if compared with experimental ones, while the air velocities seems to be affected by a significant degree of error partially due to the steady state analysis and the boundary conditions. Even if overestimated, data of mass flow rate show how the VIW can assure an efficacy change of air only by natural ventilation. A transient analysis may certainly provide a more precise determination of the behavior of the system. The availability of a large quantity of experimental data will be a useful tool for the validation of the sw. In any case the first results encourage the authors to carry on the analysis, since the VIW seems to be an efficacy system of daylight transport and natural ventilation for underground areas of buildings or rooms without any direct interface to outwards. It seems particularly suitable for large exhibition rooms or museums where the absence of windows or skylight makes it impossible daylight and natural ventilation of the environment.

\section{References}

[1] M. Santamouris, Alternative cooling techniques for building (Keynote lecture), Proceedings of the $6^{\text {th }}$ International Conference on Sustainable Energy Technologies SET 2007, Santiago de Chile, 2007, pp. 19-24.

[2] C. Baroncini, F. Chella, P. Zazzini, Numerical and experimental analysis of the Double Light Pipe, a new system for daylight distribution in interior spaces, International Journal of Low Carbon Technologies, 3/2, 2008, pp.110-125.

[3] C. Baroncini, O. Boccia, F. Chella, P. Zazzini, Experimental analysis on a $1: 2$ scale model of the Double Light Pipe, an innovative technological device for daylight transmission, Sola Energy, 84, 2010, pp.296-307.

[4] S. Varga, A. C. Oliveira, Ventilation terminal for use with light pipes in buildings, Applied Thermal Engineering 20, 2000, 1743-1752.

[5] A. C. Oliveira, A. R. Silva, C. F. Afonso, S. Varga, Experimental and numerical analysis of natural ventilation with combined light-vent pipes, Applied Thermal Engineering 21, 2001, 1925-1936.

[6] F. M. White, Fluid Mechamics, $2^{\text {nd }}$ ed. McGraw Hill, New York, 1986.

[7] S. V. Patankar. Numerical Heat Transfer and Fluid Flow. Hemisphere, Washington D.C., 1980

[8] Airpak 2.1 User's Guid Fluent Inc. April 2002.

[9] B.E. Launder, D.B. Spalding, The numerical computation of turbulent flows, Computational Method. Applied Mechanical Engineering, 3 (1974) 313.

[10] P.V. Nielsen, F. Allard, H.B. Awbi, L. Davidson, A. Schalin, Fluidodinamica computazionale applicata alla progettazione della ventilazione ed. D. Flaccovio 2009. 